\title{
Outcome of Type 3 Open Tibial Diaphyseal Fractures Managed with a Limb Reconstruction System: Analysis of a 49-Patient Cohort
}

\author{
Ali Çağrı Tekin ${ }^{a} \quad$ Mehmet Selçuk Saygılıb Müjdat Adaş ${ }^{a} \quad H^{b}$ aluk Çabuk ${ }^{a}$ \\ Samet Murat Arslan ${ }^{\text {a }}$ Süleyman Semih Dedeoğlu ${ }^{a}$ \\ a Department of Orthopaedics and Traumatology, Okmeydanı Training and Research Hospital, and \\ ${ }^{b}$ Metin Sabancı Baltalimanı Bone Disease Training and Research Hospital, Istanbul, Turkey
}

\section{Key Words}

Open tibia fracture $\cdot$ Rigid fixation $\cdot$ Single-plane external fixator

\begin{abstract}
Objective: To evaluate functional and radiological results following treatment with the single-plane external fixator limb reconstruction system (LRS) for open tibial diaphyseal fractures resulting from high-energy trauma. Subjects and Methods: From a total of 62 patients who were operated on between 2011 and 2014 for open tibial diaphyseal fractures resulting from high-energy trauma, 50 tibias from 49 patients (males: 32, females: 17) were classified as type 3 according to the Gustilo-Anderson open fracture classification, and definitive treatment was applied with the LRS. The patients ranged in age from 20 to 36 years. Time to union, time of external fixator usage, complications and functional results according to the Johner-Wruhs criteria were recorded. Results: The mean follow-up period was $23 \pm 12$ months (range: 11-44). Of the 50 tibias, full union was achieved with the LRS in 48 (96\%). No shortness or deformity was observed in any patient. Knee and ankle range of movement were measured as full in all patients at the final follow-up examination after removal of the LRS. The mean time to union was
\end{abstract}

\begin{tabular}{|c|c|}
\hline KARGER & $\begin{array}{l}\text { (c) } 2015 \text { S. Karger AG, Basel } \\
1011-7571 / 15 / 0253-0270 \$ 39.50 / 0\end{array}$ \\
\hline $\begin{array}{l}\text { E-Mail karger@karger.com } \\
\text { www.karger.com/mpp }\end{array}$ & $\begin{array}{l}\text { This is an Open Access article licensed under the terms of the } \\
\text { Creative Commons Attribution-NonCommercial 3.0 Un- } \\
\text { ported license (CC BY-NC) (www.karger.com/OA-license), } \\
\text { applicable to the online version of the article only. Distribu- } \\
\text { tion permitted for non-commercial purposes only. }\end{array}$ \\
\hline
\end{tabular}

$20.4 \pm 4$ weeks (range: 16-24). The mean time of external fixator use was 20 weeks (range: 16-24 weeks). Conclusion: In this study, for the definitive treatment of open tibia diaphyseal fractures, the LRS was an optimal and safe choice that offered single-stage surgery.

(c) 2015 S. Karger AG, Basel

\section{Introduction}

The annual incidence of open fractures of long bones has been estimated to be 11.5 per 100,000 people, with $40 \%$ occurring in the lower limbs, commonly at the tibial diaphysis [1]. Open fractures comprise $23.5 \%$ of all tibial shaft fractures [2]. The initial evaluation of a patient with an open fracture of a limb should always follow the principles and guidelines of the Advanced Trauma Life Support System (ATLSS) [3]. Other concomitant serious and possibly life-threatening injuries should also be considered. The main outcome in an open tibial fracture is to restore the extremity to its previous status using treatment that allows for a timely return to work and social life and that is without complications [4]. In the treatment of open fractures, which continues to be a matter of debate, intramedullary nailing has gained wide acceptance in 
Fig. 1. Anteroposterior and lateral images of Gustilo-Anderson type 3B fracture of the tibia.
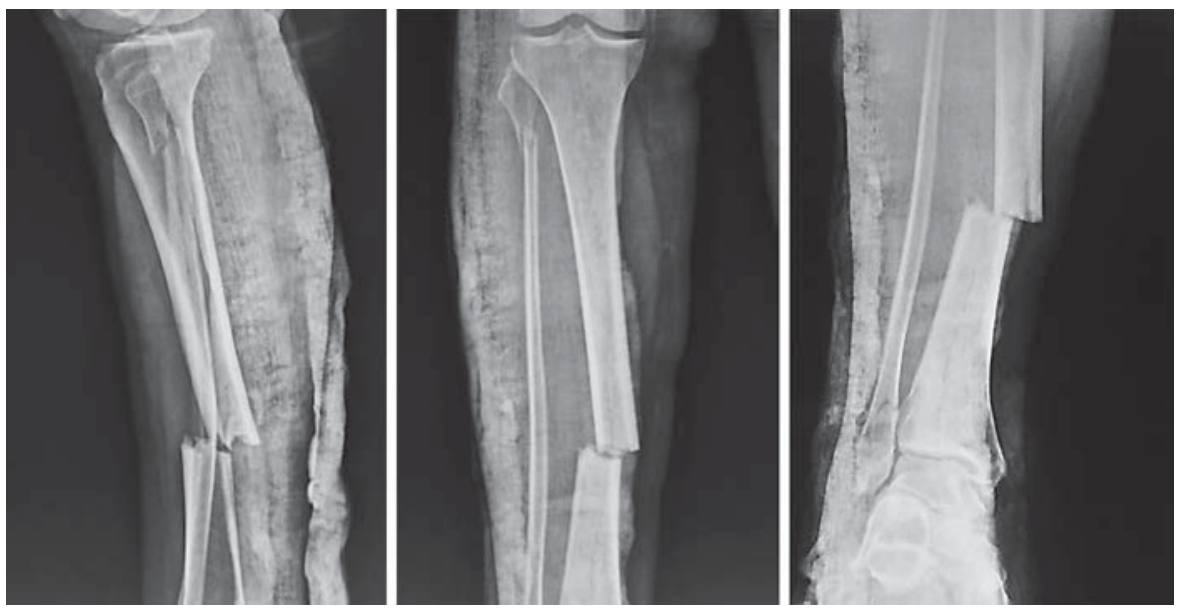

Gustilo-Anderson grade 1 and grade 2 open tibia fractures [5]. External fixation is often used for more severe grade 3 fractures, where soft tissue injury may not allow for intramedullary fixation [4]. In this study, we evaluated the treatment outcomes of open tibial fractures using the rigid limb reconstruction system (LRS), which is mostly used in the treatment of deformities and provides bone transport and fixation.

\section{Subject and Methods}

This protocol was approved by our institutional review boards to perform this retrospective study. The study initially included 62 patients with tibial open fractures that were treated with the LRS type monolateral rigid fixator between June 2011 and March 2014. Exclusion criteria were cases of grade 1,2 and $3 \mathrm{C}$ fractures as well as initial bone loss greater than $1 \mathrm{~cm}$. Based on this, 50 tibias of 49 patients (males: 32, females: 17) were included in the study.

In all patients, there was a concomitant ipsilateral fibula fracture, but no additional surgical fixation was applied for the fibular fracture (fig. 1). At the final postoperative follow-up examination, the union status was evaluated using radiography. Fractures were considered clinically united when walking without pain was possible. On radiographs, union was defined as callus on two radiographic views with disappearance of the fracture line. Shortness and angulation deformity were evaluated in anteroposterior and lateral orthoroentgenographs by an independent examiner (H.Ç.). In the clinical examination, knee and ankle range of movement were examined by an independent examiner in comparison to the contralateral healthy side using a goniometer. Time to union, time of external fixator usage, complications and functional results according to the Johner-Wruhs criteria [6] were evaluated.

\section{Surgical Technique}

With the patient under general anesthesia and after sterile draping of the extremity, debridement and irrigation were done. Under fluoroscopy guidance, at the closest point to the fracture
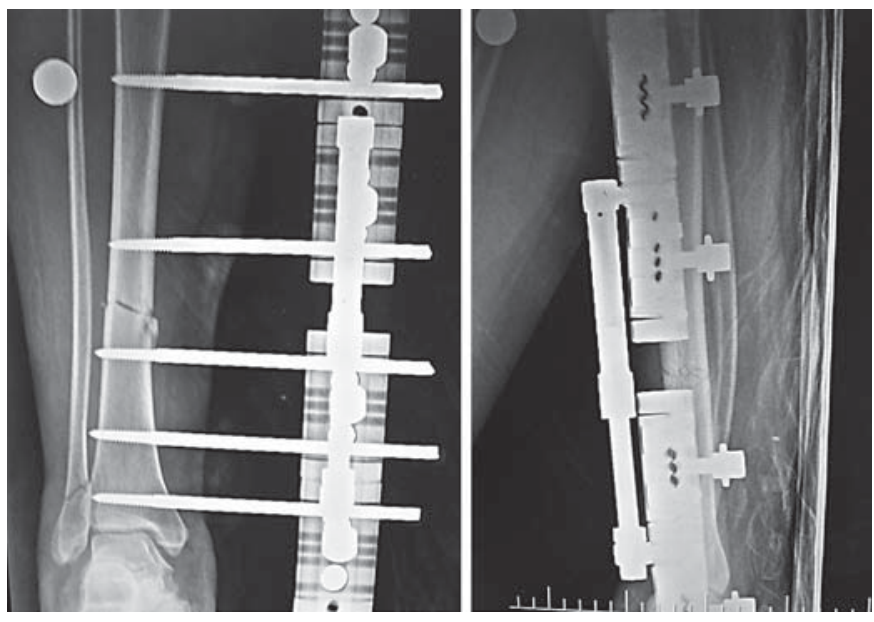

Fig. 2. Postoperative images of a Gustilo-Anderson type 3B fracture of the tibia.

line, proximal and distal to the fracture line and vertical to the bone anatomic axis, a hydroxyapatite-covered Schanz screw was drilled in and then advanced from medial to lateral, parallel to the floor. By fixing the Schanz screws on the LRS with 2 separate clamps, reduction was achieved under fluoroscopy. The system was fixed by advancing one more Schanz screw from the clamps on the LRS to the tibia to be parallel to the tibia proximal and distal joint surfaces. By advancing one more screw between the pairs of Schanz screws applied to the fracture's proximal and distal fragments, each fracture fragment was fixed to the LRS with at least 3 Schanz screws (maximum 4; fig. 2). The distraction-compression device was placed on the holes over the clamps in a way that passed over the fracture line. It was confirmed that the system was rigid by checking all of the screws on the system. In grade $3 \mathrm{~B}$ open fractures, all compartments were loosened by opening with a posterolateral fasciotomy before fixation. All fasciotomy areas were closed with a split thickness skin graft 1 week later. 
In patients with grade $3 \mathrm{~A}$ open fractures, knee and ankle exercises were initiated on postoperative day 1 . Depending on the level of pain, partial weight-bearing was permitted during the early period (1-7 days). After 3 weeks, all patients were permitted up to half full weight-bearing on the operated side and were allowed to walk with a pair of underarm crutches. After 6 weeks, all patients continued with a single crutch, and after 2 months, the patients were permitted to walk without crutches.

\section{Statistical Analysis}

SPSS for Windows version 15.0 software (SPSS Inc., Chicago, Ill., USA) was used for statistical analysis. Descriptive statistics of the data mean, standard deviation, median minimum, maximum, frequency and ratio values were used to describe study population. A Kolmogorov-Smirnov test was used for the distribution of variables. A $\chi^{2}$ test was used to compare qualitative variables. $\mathrm{p}<0.05$ was considered statistically significant.

\section{Results}

The mean age of the patients was 28 years (range: $20-$ 36). Based on the Gustilo-Anderson classification, 39 (78\%) of the tibias were type $3 \mathrm{~A}$ open fractures and 11 (22\%) were type 3B open fractures. Twenty-nine (58\%) were left tibia fractures, and $21(42 \%)$ were right tibia fractures. According to the AO/OTA classification, 21 (42\%) were type 42 -B1 fractures, 10 (20\%) were type 42 B2 fractures, 17 (34\%) were type 42-A2 fractures and 2 (4\%) were type $42-\mathrm{C} 2$ fractures. The injury was due to traffic accidents in 30 cases $(61.2 \%)$, a fall from height in 11 cases $(22.45 \%)$ and a workplace accident in 8 cases (16.35\%). The hospitalization period for grade $3 \mathrm{~A}$ was 2-4 days, and the hospitalization period for grade $3 \mathrm{~b}$ was $8-15$ days.

The mean follow-up period was $23( \pm 11)$ months (range: 11-44). Full union was achieved with the LRS in 48 tibias (96\%; fig. 3). In one patient with bilateral segmental grade $3 \mathrm{~A}$ fractures and nonunion in both tibias, the LRS was removed and then grafting and intramedullary nailing was applied. Union was achieved after nailing and grafting. No statistically significant difference was found in union times between Gustilo-Anderson grades $3 \mathrm{~A}$ and $3 \mathrm{~B}(\mathrm{p}>0.05)$. The mean time to union was $20.4 \pm 4$ weeks (range: 16-24). The mean time of external fixator use was 20 weeks (range: 16-24). No major complication was observed in any patient. However, pin site infection was observed in 5 patients $(10 \%)$, which was successfully treated with oral antibiotics (amoxicillin + clavulanate) without changing the pin. No neurovascular deficit was determined in any patient. Throughout the treatment period, no implant
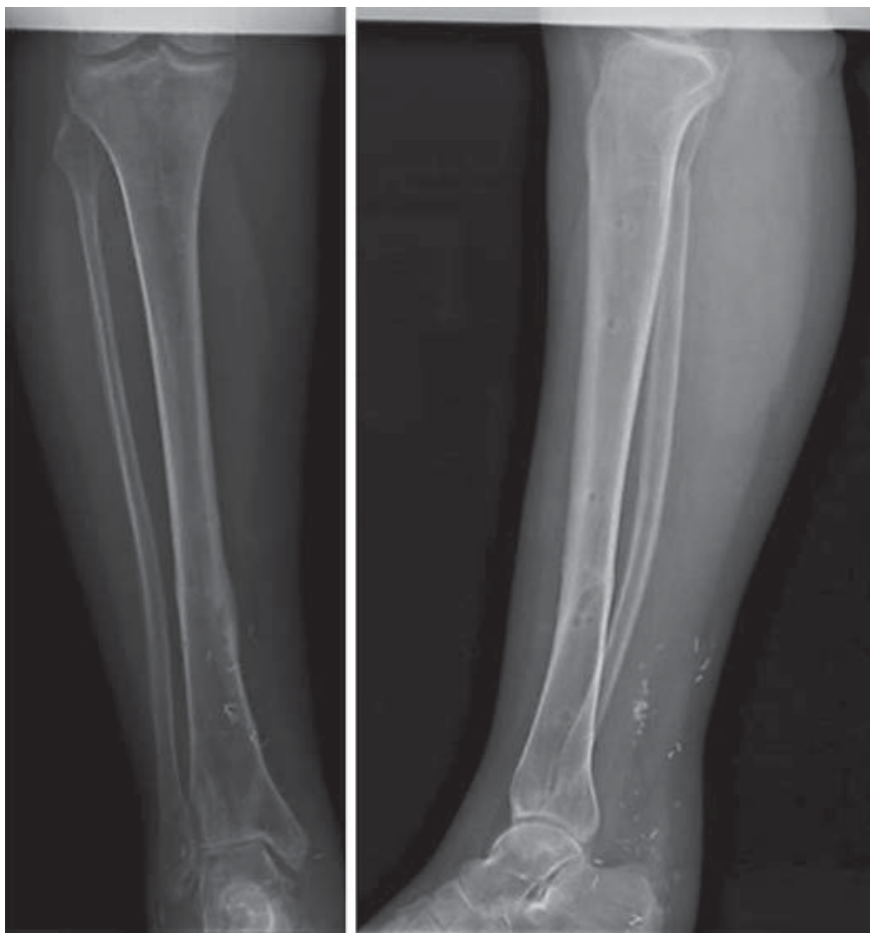

Fig. 3. Images of a Gustilo-Anderson type 3B tibia fracture treated with the LRS at 30 months.

Table 1. Gustilo-Anderson classification and clinical results of patients

\begin{tabular}{llllll}
\hline $\begin{array}{l}\text { Gustilo- } \\
\text { Anderson }\end{array}$ & $\begin{array}{l}\text { Knee } \\
\text { ROM }\end{array}$ & $\begin{array}{l}\text { Ankle } \\
\text { ROM }\end{array}$ & Deformity Rotation & $\begin{array}{l}\text { Length, } \\
\mathrm{mm}\end{array}$ \\
\hline 3A (39 tibias) & $132 \pm 6^{\circ}$ & $55 \pm 5^{\circ}$ & $3.64 \pm 2^{\circ}$ & $2.7 \pm 2.2^{\circ}$ & $3 \pm 1$ \\
3B (11 tibias) & $130 \pm 10^{\circ}$ & $50 \pm 4^{\circ}$ & $2.7 \pm 2^{\circ}$ & $3.1 \pm 1.6^{\circ}$ & $2 \pm 2$ \\
\hline
\end{tabular}

$\mathrm{ROM}=$ Range of motion

failure or Schanz screw breakage was observed. Extraction was applied in the operating theater under general anesthesia. After extraction, a protective brace was applied. No pathological movement was determined in any patient. No refracture was observed during the follow-up period.

No shortness or deformity was observed in any patient with Gustilo-Anderson grade 3B, except for one patient with bilateral segmented grade $3 \mathrm{~A}$ fractures united with no shortness or deformity (table 1). One patient with bilateral fracture had nonunion, varus alignment with $15^{\circ}$ on the right side and $10^{\circ}$ on the left side, extreme pain, 


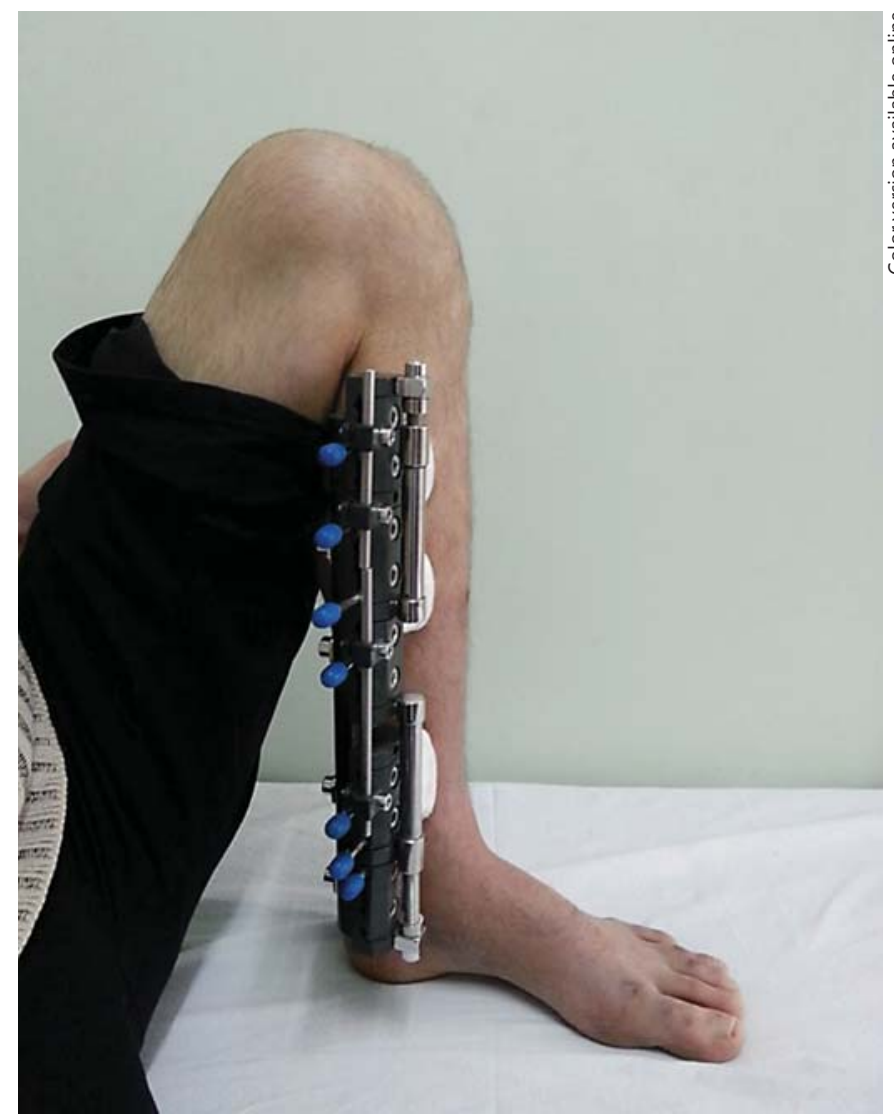

Fig. 4. Knee flexion of the patient with the LRS system on the 15th day after operation.

and was unable to bear weight on the fractured leg. The knee range of motion was between $120^{\circ}$ and $140^{\circ}$, and ankle range of movement was between $20^{\circ}$ dorsiflexion and $40^{\circ}$ plantar flexion at the final follow-up examination after removal of the LRS (fig. 4, 5).

Based on the Johner-Wruhs criteria, 35 (70\%) of the fixations were very good and $12(24 \%)$ were good. One (2\%) fixation was moderate, with moderate pain, and 2 (4\%) were poor because of nonunion and deformity. Four of the patients experienced minimal pain during weightbearing activities, and the remainder of the patients experienced occasional pain. No statistically significant difference was found between the Johner-Wruhs criteria and Gustilo-Anderson grade ( $\mathrm{p}>0.05)$.

Forty-seven (96\%) of the patients returned to work within 18-32 weeks, but 2 patients did not return to work until 51 weeks. One of these patients had a bilateral segmental fracture and the other had a grade $3 \mathrm{~B}$ fracture and a moderate score according to the JohnerWruhs criteria.
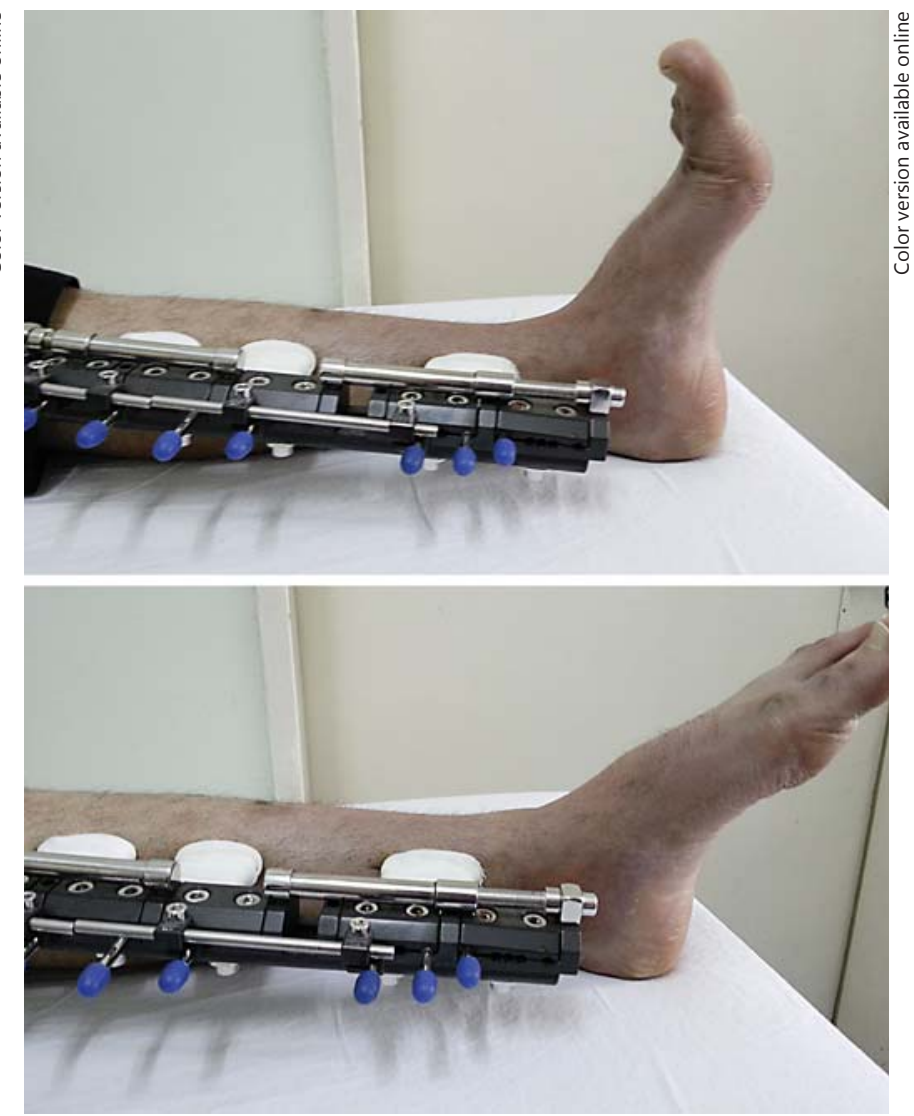

Fig. 5. Ankle dorsiflexion and plantar flexion with the LRS on the 15 th day after operation.

\section{Discussion}

In this study, we showed that the LRS was a good option in treatment of grades $3 \mathrm{~A}$ and $3 \mathrm{~B}$ open tibia fractures. It had a high union rate and was compatible with intramedullary nailing. Residual deformity, shortness and refracture rates were low. Knee and ankle range of movements were in functional limits after removal of the LRS. These findings confirmed the previous study of Dickson et al. [7]

The 5.3-day mean hospitalization period for our patients was shorter than the 12 days Bråten et al. [8] reported for hospitalization of open tibia fractures treated by external fixation and 16-day hospitalization period for open tibia fractures treated with intramedullary nailing. The difference in hospitalization period could be because the time between injury and surgery was less than 1 day and due to the high patient turnover rate in the clinic.

At the end of the treatment, no loss was determined in ankle or knee movements compared to the healthy knee 
and ankle. In previous studies related to circular external fixator and intramedullary nailing, losses of up to an average of $40^{\circ}$ in ankle movement have been reported [9-12]. The results of the current study provide evidence that Schanz screws applied in a single plane from the medial tibia do not prevent ankle or knee movement of the patient, but no supporting data could be found in the literature.

Early mobilization of the patients in the current study was achieved by early weight-bearing (1-7 days), but despite being able to walk unassisted with the external fixator, no patient was able to return to work before the external fixator was removed. The mean time to union was 20.4 weeks (range: 16-24). In a literature review study by Dickson et al. [7], the longest time to union was observed to occur with reamed screws (mean: 40.9 weeks), and this period was determined to have a mean of 39 weeks in treatment with a monolateral external fixator. Although the time to union of the patients in the current study was shorter than that of patients treated with a monolateral external fixator as reported in the literature, it was consistent with the results of groups treated with unreamed nails, plate and circular external fixator. Union of both segments of the tibial fracture was not observed in $1 \mathrm{pa}-$ tient. In a study of segmental tibial fractures by Giotakis et al. [13], nonunion was reported in 2 (10\%) of 20 segmented fractures treated with an external fixator. In the current series, there was an insufficient number of segmental fractures to be able to make a comparison. As a complication, refracture was not observed in any of the current study patients.

In the current study, the external fixator was not removed and dynamization was not applied until radiological findings of union were seen. In a study by Sener et al. [14], refracture was observed in 1 patient (5\%). When union was observed radiologically in 3 cortices, by dynamization of the LRS, it was examined whether the patient experienced pain with full weight-bearing [15]. In patients with no pain on full weight-bearing, the external fixator was removed under general anesthesia in the op- erating theater. Following removal of the fixator, no brace or plaster cast was applied.

Generally, in open fractures, an external fixator is used temporarily until definitive treatment is applied to the patient [16]. A dominant view exists in the literature regarding the idea that external fixator application results in increased nonunion and infection rates. Following monolateral external fixator application, some of the infection rates that have been observed in the literature include $25 \%$ superficial infection and $10 \%$ deep infection [17-21]. In the current study, no deep infection was encountered. Superficial infection was observed in $5(10 \%)$ patients, and in all cases this infection responded to oral antibiotics. The lower rate of infection than that reported in the literature can be attributed to the effect of using hydroxyapatite-coated Schanz screws [22, 23].

The use of an external fixator with moveable heads has been reported in the literature to be a definitive treatment option for open tibial fractures $[4,24]$. In the current study, a monolateral, fixed head single-plane LRS that provided rigid fixation and the possibility of single-stage treatment was preferred so as to prevent reoperation.

In this study, there were some limitations. First, we did not include Gustilo-Anderson grade 3C fractures because of their poor result according to the Johner-Wruhs criteria due to neurovascular deficit. This could have increased our good results. Second, because this was a retrospective design study, treatment regimens could have been different between the patients. Lastly, our patient size was small, and larger series are needed to provide more detailed information.

\section{Conclusion}

In this study, we showed that the LRS was an optimal single-stage surgery for grade $3 \mathrm{~A}$ and $3 \mathrm{~B}$ open fractures as it offered rigid fixation for early weight-bearing and resulted in low residual deformity and shortness rates, and shorter hospital stays.

\section{References}

Howard M, Court-Brown CM: Epidemiology and management of open fractures of the lower limb. Br J Hosp Med 1997;57:582-587.

2 Court-Brown CM, McBirnie J: The epidemiology of tibial fractures. J Bone Joint Surg Br 1995;77:417-421.

-3 Kortbeek JB, Al Turki SA, Ali J, et al: Advanced trauma life support, 8th edition, the evidence for change. J Trauma 2008;64:1638-1650.
4 Parmaksizoglu AS, Yalaman O, Ozkaya U, et al: External fixators and results applied in open tibial fractures. Acta Orthop Traumatol Turc 1994;28:94-97.

5 Djahangiri A, Garofalo R, Chevalley F, et al: Closed and open grade I and II tibial shaft fractures treated by reamed intramedullary nailing. Med Princ Pract 2006;15:293-298.

Tekin/Saygılı/Adaş/Çabuk/Arslan/ Dedeoğlu 
-6 Johner R, Wruhs O: Classification of tibial shaft fractures and correlation with results after rigid internal fixation. Clin Orthop Relat Res 1983;178:7-25.

7 Dickson DR, Moulder E, Hadland Y, et al: Grade 3 open tibial shaft fractures treated with a circular frame, functional outcome and systematic review of literature. Injury 2015; 46:751-758.

8 Bråten M, Helland P, Grøntvedt T, et al: External fixation versus locked intramedullary nailing in tibial shaft fractures: a prospective, randomised study of 78 patients. Arch Orthop Trauma Surg 2005;125:21-26.

>9 Francel TJ, Vander Kolk CA, Hoopes JE, et al: Microvascular soft-tissue transplantation for reconstruction of acute open tibial fractures: timing of coverage and long-term functional results. Plast Reconstr Surg 1992;89:478-487.

10 Tielinen L, Lindahl JE, Tukiainen EJ, et al Acute unreamed intramedullary nailing and soft tissue reconstruction with muscle flaps for the treatment of severe open tibial shaft fractures. Injury 2007;38:906-912.

11 Georgiadis GM, Behrens FF, Joyce MJ, et al: Open tibial fractures with severe soft-tissue loss. Limb salvage compared with below-theknee amputation. J Bone Joint Surg Am 1993; 75:1431-1441.
12 Gopal S, Giannoudis PV, Murray A, et al: The functional outcome of severe, open tibial fractures managed with early fixation and flap coverage. J Bone Joint Surg Br 2004;86:861867.

13 Giotakis N, Panchani SK, Narayan B, et al: Segmental fractures of the tibia treated by circular external fixation. J Bone Joint Surg Br 2010;92:687-692.

14 Sener M, Aydin H, Erkut A, et al: Treatment of type 3 open tibial fractures with dynamic axial fixator. Acta Orthop Traumatol Turc 1998;32:202-207.

15 Whelan DB, Bhandari M, McKee MD, et al: Interobserver and intraobserver variation in the assessment of the healing of tibial fractures after intramedullary fixation. J Bone Joint Surg Br 2002;84:15-18.

16 Sorkin AT: When do you use a spanning fixator across the knee? in Virkus WW (ed): Curbside Consultation in Fracture Management: 49 Clinical Questions. Thorofare, Slack, 2008, pp 111-115.

17 Court-Brown CM, Wheelwright EF, Christie J, et al: External fixation for type III open tibial fractures. J Bone Joint Surg Br 1990;72: 801-804.
18 Webb LX, Bosse MJ, Castillo RC, et al: Analysis of surgeon-controlled variables in the treatment of limb-threatening type-III open tibial diaphyseal fractures. J Bone Joint Surg Am 2007;89:923-928.

19 Naique SB, Pearse M, Nanchahal J: Management of severe open tibial fractures: the need for combined orthopaedic and plastic surgical treatment in specialist centres. J Bone Joint Surg Br 2006;88:351-357.

20 Bach AW, Hansen ST Jr: Plates versus external fixation in severe open tibial shaft fractures. A randomized trial. Clin Orthop Relat Res 1989;241:89-94.

21 Shannon FJ, Mullett H, O’Rourke K, et al: Unreamed intramedullary nail versus external fixation in grade III open tibial fractures. J Trauma 2002;52:650-654.

22 Moroni A, Pegreffi F, Cadossi M, et al: Hydroxyapatite-coated external fixation pins Expert Rev Med Devices 2005;2:465-471.

23 Moroni A, Heikkila J, Magyar G, et al: Fixation strength and pin tract infection of hydroxyapatite-coated tapered pins. Clin Orthop Relat Res 2001;388:209-217.

24 Pommer A, Muhr G, Dávid A: Hydroxyapatite-coated Schanz pins in external fixators used for distraction osteogenesis: a randomized, controlled trial. J Bone Joint Surg Am 2002;84-A:1162-1166. 